\title{
AC 2012-4280: ASSESSING MULTIDISCIPLINARY DESIGN IN A ROBOTICS ENGINEERING CURRICULUM
}

\section{Prof. Michael A. Gennert, Worcester Polytechnic Institute}

Michael A. Gennert is Director of the Robotics Engineering Program at Worcester Polytechnic Institute, where he is professor of computer science and professor of electrical and computer engineering. He has worked at the University of Massachusetts Medical Center, Worcester, Mass., the University of California/Riverside, General Electric Ordnance Systems, Pittsfield, Mass., and PAR Technology Corporation, New Hartford, N.Y. He received the B.S. in computer science, B.S. in electrical engineering, and M.S. in electrical engineering in 1980, and the D.Sc. in electrical engineering in 1987 from the Massachusetts Institute of Technology. Gennert is interested in computer vision, image processing, scientific databases, and programming languages, with ongoing projects in biomedical image processing, robotics, and stereo and motion vision. He is author or co-author of more than 100 papers. He is a member of Sigma Xi, NDIA Robotics Division, and the Massachusetts Technology Leadership Council Robotics Cluster, and a Senior Member of IEEE and ACM.

\section{Dr. Taskin Padir, Worcester Polytechnic Institute}

Taskin Padir is an Assistant Professor of electrical and computer engineering at Worcester Polytechnic Institute. He is also a faculty member in the Robotics Engineering program. He advised capstone projects that have been sponsored by NASA, Mathworks, Solidworks, National Instruments, Intel, NVidia, Maxon Motors, Tesla Motors, and Igus. Padir received the Inaugural Rho Beta Epsilon Award for Excellence in Robotics Education in 2010 and Romeo L. Moruzzi Young Faculty Award for Innovation in Undergraduate Education in 2011 for his contributions to WPI's unique undergraduate program in robotics engineering. 


\title{
Assessing Multidisciplinary Design in a Robotics Engineering Curriculum
}

\begin{abstract}
Worcester Polytechnic Institute (WPI) recently started a new undergraduate degree program in robotics engineering (RBE). As of the fall semester of 2011, the program is the seventh largest discipline at WPI in terms of undergraduate enrollment. At the core of the curriculum are four signature courses called Unified Robotics I-IV. The goal of these courses is to introduce students to the multidisciplinary theory and practice of robotics engineering, integrating the fields of computer science, electrical engineering and mechanical engineering. The sophomore level courses, RBE 2001 and RBE 2002, introduce students to the foundational concepts of robotics such as kinematics, pneumatics, circuits, electric motors, sensors, signal processing and embedded system programming. The junior level courses, RBE 3001 and RBE 3002, build on this foundation to ensure that students understand the analysis of selected components and learn system-level design and development of a robotic system.
\end{abstract}

In addition to taking courses, WPI requires all students to complete a major qualifying project (MQP) in their major field of study. For RBE students, this requires a capstone design experience in robotics. Students typically work in teams of two to four students, although singleperson projects and larger teams are also possible. A faculty member in the major advises the work. Students are expected to take relevant coursework before the project begins. The project work itself typically starts with a formal project proposal, including literature review, clearly defined approach, and schedule with milestones. Projects conclude with a report and presentation to faculty and students. Within this structure, the capstone senior design experience serves as the binding agent for the theory and practice learned in the core courses taught in the robotics engineering curriculum.

This paper discusses the capstone design experience within a new degree program in robotics engineering in detail while attempting to address the problem of teaching multidisciplinary design to senior engineering students working on projects that aims to solve real-world problems. Learning outcomes specifically designed for the senior-design and sample projects completed by robotics engineering students illustrating our approach to designing this new robotics engineering program at the undergraduate level are presented.

As a preparation for the ABET visit that took place in fall 2010, the authors conducted a formal review of the senior capstone design experience within the multidisciplinary robotics engineering program. This paper presents the findings of this first review to assess the condition of this portion of the RBE degree program. The intent was to assess the MQPs and determine whether they meet the educational goals of the program. For the purpose of this review, the period was defined to include MQPs completed during 2009-2010 academic year. A total of eight projects were completed during that period involving $14 \mathrm{RBE}$ students. The review involved reading all of the project reports and a content analysis performed on seven MQP reports publicly available. During the review, a set of summary sheets were completed by the review committee and faculty advisors for each project. The paper provides the detailed statistical data upon which this review was based on, assessment methodology followed and a discussion on the findings. 


\section{Introduction}

Considering the fact that engineering students of 2010 will still be professionally active in 2050 , their engineering education today should be broad enough for them to generate solutions to meet the new requirements of the global industry and society [1-3]. To achieve a smooth transition from academia to industry, there should be an agreement between the desired outcomes of engineering curricula and the desired attributes of an engineer defined by the industry. In other words, the graduates of engineering programs must have a set of basic skills to meet the needs of the industry and society. A good understanding of engineering science, a good understanding of engineering design process, a multidisciplinary perspective, excellent communication skills, high ethical standards, critical and creative thinking, an appreciation of the importance of teamwork, an awareness of economic, environmental and societal issues, and a desire for life-long learning are among the attributes forming the interface between the engineering education and the engineering practice $[4,5]$. In an attempt to build on this interface, engineering programs strive to meet the well-known ABET (a)-(k) criteria [5].

One key component of providing a broad education is the multidisciplinary experience gained by working on projects that are open-ended and complex and attempt to provide solutions to practical real-world problems. This is why teaching multidisciplinary design to engineering students especially at the senior level has been the motivation for engineering educators to adopt innovative approaches within engineering curricula [6-9]. Excellent examples of industry sponsored or competition-driven capstone design projects are reported in the literature [10-13]. These open-ended and complex projects attempt to provide a solution to a practical real-world problem. A majority of such problems require solutions which integrate sensing, computing and acting. Therefore, it is typical to see a multidisciplinary approach to capstone design bringing students from electrical and computer engineering, mechanical engineering and computer science. This allows students to be exposed to design problems outside of their own field.

Within the context of this real-world projects discussion, robotics as an engineering discipline is an interdisciplinary field of study which can be used to enrich and broaden engineering education; it promotes teamwork, technical competency, innovation and lifelong learning; more importantly, it proved to be an effective tool for improving the recruitment and retention of a diverse range of students $[14,15]$. As such, robotics is an excellent fit for the undergraduate engineering education of 2020 described in the NAE report titled Educating The Engineer Of 2020 [3]. In fact, over the past several decades, robotics has evolved to become a rather diverse field covering a wide spectrum of applications ranging from assistive technologies to consumer robotics products, from complex industrial robots to humanoids. This variety provides opportunities for incorporating robotics into the undergraduate engineering not only in the form of coursework but also as research or capstone design experiences. As a result, students remain engaged in engineering design throughout their undergraduate curriculum. The interdisciplinary nature of robotics makes it suitable for capstone senior design projects that aim to broaden student expertise before they enter the engineering workforce. Therefore, a capstone design experience revolving around robotics can be used to enrich and broaden engineering education. It is also a good fit teaching multidisciplinary design not only at the high level but also at the subsystem requirements level. 
This paper summarizes the findings of a review of robotics (RBE) Program Major Qualifying Projects (MQPs) at WPI that was conducted during the summer of 2010. This was the first review undertaken to assess the condition of this portion of the RBE degree program at WPI. The intent was to assess the RBE MQPs and determine whether they meet the educational goals of the program. For the purpose of this review, the period was defined to include MQPs completed during A09, B09, C10, and D10. A total of eight projects were completed during that period involving $14 \mathrm{RBE}$ students.

\section{Outcomes Assessment Context}

Robotics program faculty adopted the following Mission Statement, Educational Program Objectives and Educational Outcomes.

\section{Mission Statement}

The robotics engineering program at WPI prepares undergraduates for work and advanced study in Robotics - the combination of sensing, computation and actuation in the real world. Robotics is on the verge of rapid growth, driven by both supply and demand. The supply side is driven by decreasing cost and increasing availability of sensors, computing devices, and actuators. The demand side is driven by national needs for defense and security, elder care, automation of household tasks, customized manufacturing, and interactive entertainment. Engineers currently working in the robotics industry are mostly trained in Computer Engineering, Computer Science, Electrical Engineering, Mechanical Engineering, or Software Engineering. But no one of these disciplines provides the breadth demanded by Robotics in the future. Thus the WPI robotics engineering program aims to provide students with both the disciplinary fundamentals and interdisciplinary outlook needed for success in this dynamic and growing new professional field.

\section{Educational Program Objectives}

The robotics engineering program strives to educate men and women to

- Have a basic understanding of the fundamentals of Computer Science, Electrical and Computer Engineering, Mechanical Engineering, and Systems Engineering.

- Apply these abstract concepts and practical skills to design and construct robots and robotic systems for diverse applications.

- Have the imagination to see how robotics can be used to improve society and the entrepreneurial background and spirit to make their ideas become reality.

- Demonstrate the ethical behavior and standards expected of responsible professionals functioning in a diverse society.

\section{Educational Outcomes}

Graduating students will have:

- an ability to apply broad knowledge of mathematics, science, and engineering,

- an ability to design and conduct experiments, as well as to analyze and interpret data,

- an ability to design a robotic system, component, or process to meet desired needs within realistic constraints such as economic, environmental, social, political, ethical, health and safety, manufacturability, and sustainability,

- an ability to function on multi-disciplinary teams,

- an ability to identify, formulate, and solve engineering problems, 
- an understanding of professional and ethical responsibility,

- an ability to communicate effectively,

- the broad education necessary to understand the impact of engineering solutions in a global, economic, environmental, and societal context,

- a recognition of the need for, and an ability to engage in life-long learning,

- a knowledge of contemporary issues, and

- an ability to use the techniques, skills, and modern engineering tools necessary for engineering practice.

In addition to the educational outcomes specific to the RBE program, in 2009, WPI faculty approved a set of outcomes for the capstone design (Table 1).

Table 1: Capstone Learning Outcomes

Students who complete a Major Qualifying Project will:

(a) apply fundamental and disciplinary concepts and methods in ways appropriate to their principle areas of study

(b) demonstrate skill and knowledge of current information and technological tools and techniques specific to the professional field of study

(c) use effectively oral, written and visual communications

(d) identify, analyze and solve problems creatively through sustained critical investigation,

(e) integrate information from multiple sources,

(f) demonstrate an awareness and application of appropriate personal, societal, and professional ethical standards,

(g) practice skills, diligence, and commitment to excellence needed to engage in lifelong learning.

The review of MQPs that took place during summer 2010 is one of the assessment instruments used to measure whether the educational outcomes of the RBE program are met.

\section{Methodology}

Based on the project learning outcomes, faculty uses a variety of methods of measurement to collect data on the capstone design experience. We can divide the MQP assessment instruments into several categories.

- MQP Report Review: At regular intervals determined by the university administration, all programs undertake a significant review of the content and quality of that year's MQPs. Many of the outcomes are assessed, as well as the correlation between perceived quality and grade assigned.

- MQP Presentation Evaluations: In April every year all graduating students present their MQPs to their departments and the public. The RBE faculty evaluates every presentation using a standard form. The resulting data are mostly used to evaluate presentation skills.

- Advisor's Evaluation of MQP: Every MQP has a faculty advisor who provides an evaluation of every completed MQP. The resulting data are used to provide a view of how well MQPs are supporting outcomes. 
The specifics of the assessment process can be highlighted using an approach that is two-fold. First, the faculty advisor(s) of a completed project are asked to fill out an assessment form on which the advisor notes to what extent the completed project team, and individual team members, addressed the specific ABET capstone consideration areas (economics, safety, ...). Second, every other year two program faculty spend the summer reading and evaluating every single project report completed since the previous review. Factors are ranked on a scale of 1-5 where 1 is not at all or poorly done/not appropriate to 5 which is to a great extent or well done/ appropriate. The ranked factors include the following.

- the ABET factors (economics, safety, ...)

- appropriateness of the grade assigned

- whether the documented work represented a full 9 credits of project activity

- the level and extent of design and analysis

- the quality of the documentation

- the quality of the figures, tables, data, etc.

- whether experimentation and laboratory work was involved

- the quality and extent of the references

Finally, the Capstone Review Committee collect and summarize the oral presentation evaluations generated during project presentation day to assess the quality of the presentations, areas in need of work, and long term trends. Once the project reports have been read and analyzed, and the oral presentation reviews have been tabulated, a report is generated that summarizes the methods, data and observations, and makes recommendations for quality control and overall project program improvements. This review includes a comparison to previous reviews so that trends and problems can be identified, and the results of previously recommended improvements can be assessed. The data, summary report, and recommendations are presented and reviewed early in the next academic year so that actions can be taken to continue to improve the overall MQP experience.

For the purpose of the results of the MQP Review Report being discussed in this paper, the period was defined to include MQPs completed during A09, B09, C10, and D10. A total of eight projects were completed during that period involving $14 \mathrm{RBE}$ students. It was decided that the review procedure should involve reading all of the project reports for RBE MQPs conducted during the 2009 - 2010 academic year. In addition, a content analysis was carried out on seven MQP reports publicly available. One MQP report was not available for review as its content was made confidential by the sponsoring company. During the review, a set of summary sheets were completed by the review committee and faculty advisors for each project. A sample of the summary sheets used is included in Appendix 1. In addition, the Completion of Degree Requirement (CDR) forms for each student were also reviewed for project grading, and credit awarded to be considered. The detailed statistical data will be presented in the next section.

\section{Results - Summary of Project Characteristics}

Project Team Make-up: The average student project team size was 3.25. 12.5\% of the reviewed projects were accomplished by a single student. $37.5 \%$ consisted of two-student teams; $25 \%$ consisted of three-student teams; and $12.5 \%$ consisted of four-student teams. There was one project accomplished by a nine-student team. Table 2 presents the capstone design projects 
completed in 2010 by design teams including RBE students. The review of the project team make-up reveals that students often function on multidisciplinary teams. There were two projects completed by project teams consisting of RBE students only. As a measure of the faculty load, $50 \%$ of the projects were co-advised by 2 or more faculty members. Student to faculty ratio for all the projects was 1.7 .

Table 2: MQPs completed by project teams that included RBE students (Source: 2010 RBE Project Presentation Day Schedule).

\begin{tabular}{ll}
\hline Project Title & Team \\
\hline Force Sensing and Haptic Feedback for Robotic Surgery & $1 \mathrm{RBE}$ \\
& $1 \mathrm{ME}$ \\
$\begin{array}{l}\text { Design of a Spoken Language Interface for Collaboration with } \\
\text { an Autonomous Robot }\end{array}$ & $1 \mathrm{RBE}$ \\
Reconfigurable Modular Mobile Robot Platform & $3 \mathrm{RBE}$ \\
Pneumatic Actuator Development for MRI Robots & $2 \mathrm{RBE}$ \\
& $1 \mathrm{ECE}$ \\
$\begin{array}{l}\text { Design of an Active-Assistance Balancing Mechanism for a } \\
\text { Bicycle }\end{array}$ & $2 \mathrm{RBE}$ \\
A Multi-Weapon Auto Aiming and Trigger System for Rapidly & $1 \mathrm{RBE}$ \\
Deployable Remotely Operated Armed Support Robots & \\
Project Pele: Humanoid Robotic Programming - A Study in & $1 \mathrm{RBE}$ \\
Artificial Intelligence & $1 \mathrm{ECE}$ \\
& $1 \mathrm{ME}$ \\
Design and Realization of an Intelligent Unmanned Ground & $1 \mathrm{MA}$ \\
Vehicle & $3 \mathrm{RBE}$ \\
& $2 \mathrm{CS}$ \\
& $2 \mathrm{ECE}$ \\
\hline
\end{tabular}

Grade Distribution: The number of students receiving A grades in their project work was found to be $79 \%$. The percentage of B grades was $14 \%$ and the number of $\mathrm{C}$ grades was $7 \%$. This grade distribution appears to indicate grade inflation. The large number of A's relative to the number of $\mathrm{B}$ and C's is related to the number of projects that were judged to be worth 1 unit (9 credit hours) per student. In this review, it was determined that $29 \%$ of the projects completed were marginally worth 1 unit or did not worth 1 unit at all. However, It must be emphasized that an A grade should reflect one unit of excellent work by the student, a B grade should reflect one unit of very good work, and a $\mathrm{C}$ grade should reflect one unit of acceptable work. There is also a clear tendency to assign all students in a project team the same grade. Among 8 projects reviewed in this report, $25 \%$ had teams in which different students were assigned different grades.

Academic Level and Topical Content: The academic level-freshman, sophomore, junior, senior, and graduate level — of the electrical engineering, computer science, mechanical engineering, robotics engineering and mathematics content of the projects was estimated from the related information presented in the project report. The estimates made using a scale of 1 to 5 ( 1 for 1000-level courses, 2 for 2000-level courses, 3 for 3000-level courses, 4 for 4000-level courses, and 5 for graduate-level courses). The average value for RBE course content was estimated by the review committee to be 2.7. It is noted that highest level of RBE courses at this time is 3000- 
level (RBE 3001-3002). Although RBE 400x was offered once, only a small number of students took the class. Therefore, this result is reasonable. The average value for ECE course content was estimated by the review committee to be $2.3 .28 \%$ percent of the project involved circuit design for robot platforms. One project demonstrated competency in PCB design. The average value for CS course content was estimated by the review committee to be 3 . All projects demonstrated competency in programming and algorithms. $28 \%$ of the projects were almost completely on programming existing robotic platforms. $71 \%$ of the projects demonstrated embedded programming in C. $50 \%$ of the projects involved development of advanced algorithms. The average value for ME/ES course content was estimated by the review committee to be 2.3. $71 \%$ of the projects demonstrated mechanical design, $\mathrm{CAD}$, robot kinematics and analysis. The average value for MATH course content was estimated by the review committee to be 2.1. $43 \%$ of the project reports demonstrated robot kinematics using linear algebra. $14 \%$ of the projects demonstrated very minimal use of mathematical foundations for robotics. The indicator for this low-level of mathematics content can appear to be concerning. However, it is also noted that linear algebra, probability and differential equations, all 2000-level courses, are the highest level of mathematics required for the program. These results are fully consistent with our expectations for the MQP given the course requirements for the RBE program.

In order to assess the multidisciplinary nature of the RBE program, a content analysis was also carried out on 7 project reports which were available to the review committee. 86\% of the reports demonstrated multidisciplinary knowledge of robotics covering CS, ECE and ME topics. One project was on software development and programming and fell short on demonstrating any ECE or ME knowledge. Appendix 2 lists frequently used terminology used in the projects. It is evident from this list that RBE projects are multidisciplinary in nature (Figure 1).

\section{Results and Discussion}

The following is a summary of the major results of the 2010 robotics MQP review:

- The general educational goals of the MQP in the RBE program are being met.

- The design content of projects is high - as it should be - and is consistent with capstonedesign expectations.

- The content levels of projects in RBE, CS, ECE, ME/ES, and mathematics appear to be aligned with the level of courses required by the program.

- Some elements of the ABET design definition - namely, factors such as: safety, reliability, aesthetics, ethics, and social impact - are not currently emphasized as well as they should be (Figures 2-4).

- Documentation quality must be improved. It was evident that a through literature survey, a well-explained design process, testing procedures and critical discussion of project results are not being included or are lacking details in project reports. The documentation should include a well-written design approach and adequate descriptions of the results of analysis, simulation, and trade-off studies used to synthesize the design from established specifications and objectives. 
- Although overall evaluations for the MQP oral presentations by faculty and students were quite good, two questions (analysis of results and design experimentation) were ranked low consistently. This was also observed in project reports.

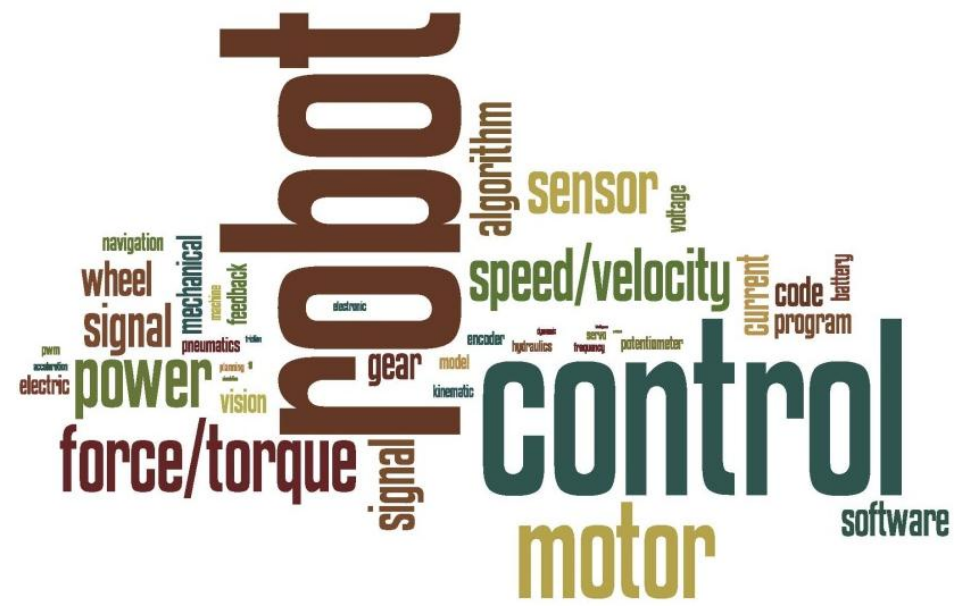

Figure 1: A content analysis carried out on robotics MQP reports reveals that robotics is multidisciplinary.

The overall conclusion of the review was that while the MQP process and the projects themselves were basically sound and were meeting the educational objectives of the Institute, it is essential that additional attention be paid to capstone design and outcomes-assessment criteria.

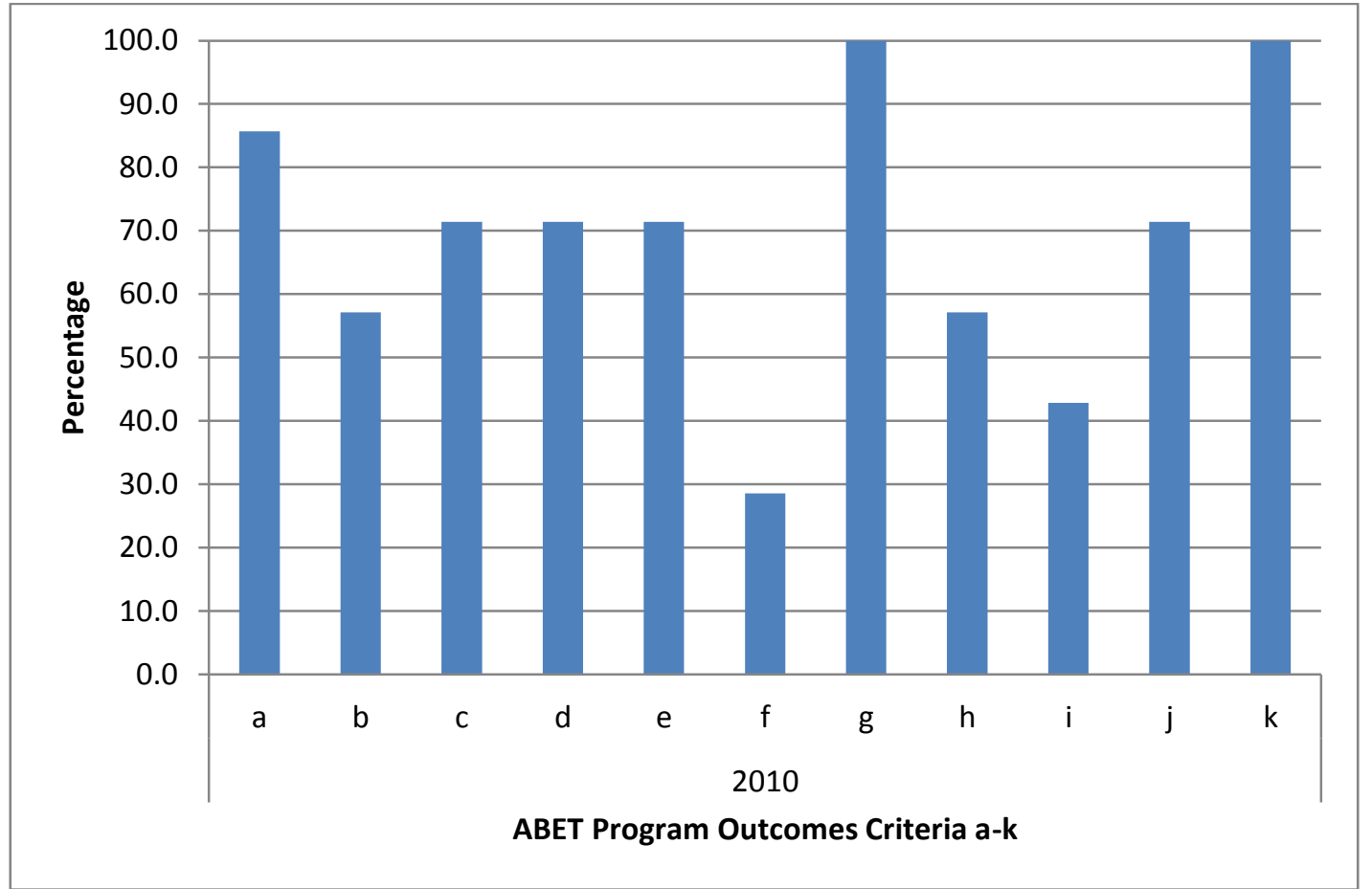

Figure 2: Assessment of the RBE projects in relation to ABET Criterion 3(a-k) by the review committee as demonstrated by the final project reports. (Number of projects $=7$ ) 


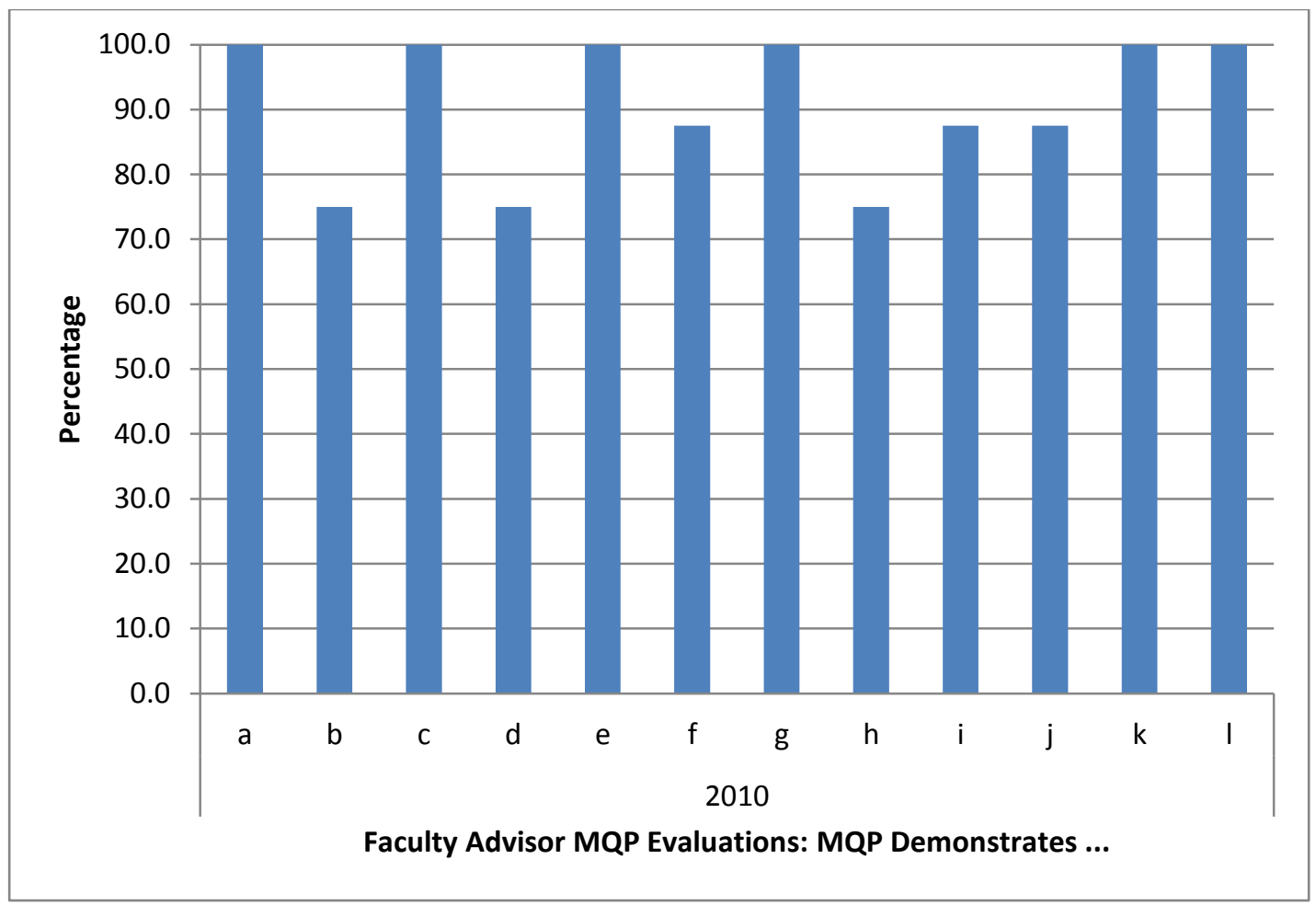

Figure 3: Assessment of the RBE projects by the faculty advisor as reported by the summary sheets. (Number of projects $=8$ )

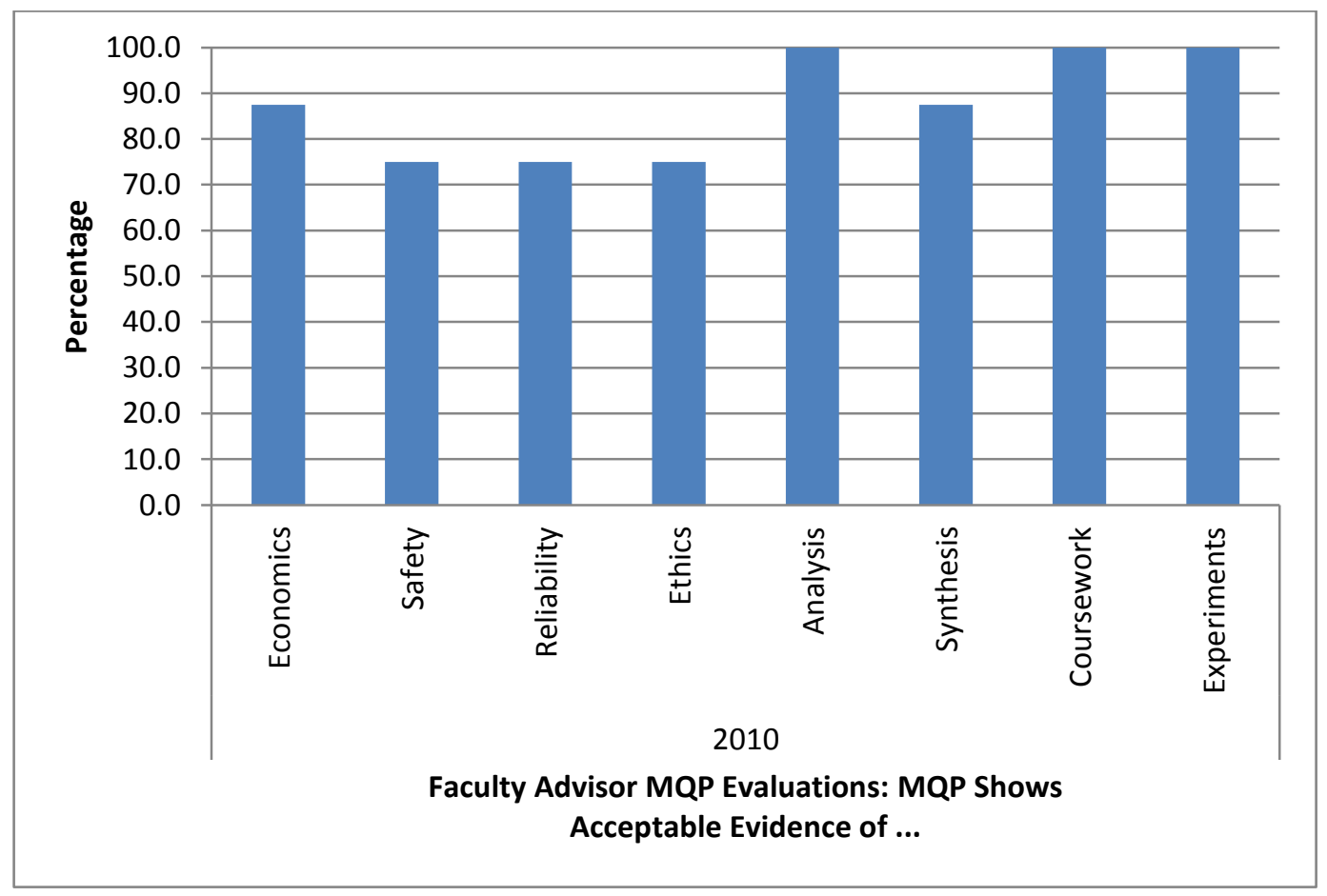

Figure 4: Assessment of the RBE projects by the faculty advisor as reported by the summary sheets. (Number of projects $=8$ ) 


\section{Conclusion}

We presented the methodology used and results of a first formal attempt to review senior capstone design projects in a robotics engineering program. As compared to similar reviews conducted by CS and ECE Departments at Worcester Polytechnic Institute, issues in the documentation quality, design approach and level of the report contents have been found to be common across programs. The committee will continue to review the projects biennially. The next scheduled such review will take place in summer of 2012. At that time, the findings of this review will make a comparative analysis possible.

\section{Bibliography}

1. NSF National Science Board, Moving Forward to Improve Engineering Education, 2007.

2. Innovate America, Council on Competitiveness National Innovation Initiative Summit and Report, 2005.

3. National Academy of Engineering, Educating the Engineer of 2020: Adapting Engineering Education to the New Century, 2005.

4. Boeing Co., "Desired attributes of an engineer", http://www.boeing.com/educationrelations/attributes.html

5. ABET Engineering Accreditation Commission, "Criteria for Accrediting Engineering Programs", 2009.

6. Dutson, A. J., Todd, R. H., Magleby, S. P., Sorensen, C. D., "A Review of Literature on Teaching Engineering Design Through Project-Oriented Capstone Courses", Journal of Engineering Education, 1997.

7. Miller, R.L., Olds, B.M., "A Model Curriculum for a Capstone Course in Multidisciplinary Engineering Design", Journal of Engineering Education, 1994.

8. Dombach, M., Knight, M., Rogers, C., "Teaching Seniors Through Developing Multidisciplinary Academies", Proceedings of CCLI Conference, The Power of Interdisciplinary/Multidisciplinary Courses and Curricula, 2007.

9. Hyman, B. L., "From Capstone to Cornerstone: A New Paradigm for Design Education", International Journal of Engineering Education, vol. 17, pp. 416-420, 2001.

10. Todd, R.H., Sorensen, C.D., Magleby, S.B., "Designing a Senior Capstone Course to Satisfy Industrial Customers", Journal of Engineering Education, 1993.

11. Paulik M. J., Krishnan M., "A Competition-Motivated Capstone Design Course: The Result of a Fifteen-Year Evolution", IEEE Transactions on Education, vol. 44, 2001.

12. Lumpp J., Jacob J., Smith S., Smith W., "BIG BLUE: A Multidisciplinary Capstone Engineering Design Project", Proceedings of the 2006 ASEE Annual Conference \& Exposition, 2006

13. Padir T, Rasaiah J.P., Worden A., Richards A., Claus J., Horrigan T., Lucarelli A., "A portable robotic workcell: Building robotics technology partnerships", Proceedings of 2008 IEEE International Conference on Technologies for Practical Robot Applications, 2008.

14. Mataric M.J., "Robotics Education for All Ages", Proceedings AAAI Spring Symposium on Accessible, Handson AI and Robotics Education, 2004.

15. McKee G.T., "The Robotics Body of Knowledge”, IEEE Robotics \& Automation Magazine, vol.14 no.1, pp. 18-19, 2007. 


\title{
Appendix 1: 2010 Project Outcomes and Assessment Form
}

\author{
2010 Project Outcomes and Assessment \\ Robotics Engineering
}

\begin{abstract}
MQP Title:
Students:

MQP Code:
\end{abstract}

(please include)

Advisor:

This Major Qualifying Project, on balance, is judged to satisfy the Capstone Design degree requirement and illustrates the following ${ }^{1}$ :

\section{MOP DEMONSTRATES:}

The following are characteristics which every engineering student should possess to some extent at the conclusion of his/her engineering education. The MQP provides a substantial opportunity for students to learn and/or to demonstrate these characteristics. Please indicate which of the following characteristics were demonstrated in this MQP.
( ) Appropriate Use of Math/Science/Engineering Knowledge
( ) Design of Experiments/ Data Analysis
( ) Design to Specifications
( ) Functioning Multidisciplinary Team
( ) Identify/Formulate/Solve Engineering Problem
( ) Ability to Communicate Effectively
( ) Sensitivity to Global/Societal Context
( ) Need for Life-time Learning
( ) Sensitivity to Contemporary Issues
( ) Use of Modern Engineering Tools and Techniques
( ) Multidisciplinary Robotics Knowledge

\section{MOP SHOWS ACCEPTABLE EVIDENCE OF:}

The following items relate specifically to engineering design. As the major (capstone) design experience for most WPI students, the MQP is the activity where students would learn and demonstrate these characteristics. Please indicate which of the following characteristics were demonstrated in this MQP.
( ) Economic Considerations
( ) Safety Considerations
( ) Analysis
( ) Synthesis
( ) Reliability Considerations
( ) Aesthetic/Ethical/Social Impact
( ) Integration of Previous Course Work
( ) Experimental Work

\section{SPONSORSHIP:}

Was this project sponsored? (Please circle) YES

If $y$ es please name sponsoring company/agency below:

NO

\section{LOCATION:}

Where was this project located? (Please circle)

ON-CAMPUS

OFF-CAMPUS

If this project was completed off campus (fully or even partially such as commuting one day a week), please describe the interaction with the sponsor, and how much time was spent off campus at the sponsor's location.

COMMENTS: (particularly with regard to aspects which may not be apparent in the report)

\section{Faculty Signature:}

1 For multi-student MQP's, please indicate which, if any, of the indicated items do not apply to all of the project students. 


\section{MQP Demonstrates}

The following paragraphs are intended as a guide to aid in consistently interpreting the "MQP Demonstrates" portion of the Project Outcomes and Assessment form.

Appropriate Use of Math / Science / Engineering Knowledge - The MQP demonstrates that the student is aware of the phenomenology of the problem being solved at a depth greater than that of a layperson and is able to use this deeper understanding to determine an appropriate solution space for the problem. This understanding should be illustrated by discussing the problem and the proposed solution in appropriate mathematical or engineering terminology.

Design of Experiments / Data Analysis - Tests and measurements are made in a structured, controlled manner with a specific purpose. Data obtained from measurements is analyzed in valid and meaningful ways. Correlations between expected and observed results and anomalies are explained appropriately.

Design to Specification - The design goals of the MQP are clearly stated. Discussions of design address specific design goals and conclusions, experiments, and analysis is provided to identify which specifications were satisfied. Explanations are provided to justify any specifications which were unattainable.

Functioning Multidisciplinary Team - The MQP team consists of people from more than one engineering or science discipline. For example, a multidisciplinary team might consist of RBE, CS, ECE and/or ME majors.

Identify/Formulate/Solve and Engineering Problem - The process of decomposing a problem into its components is clearly presented. The presentation includes a discussion of the problem, a presentation of sensible alternate solutions, and a justification of the particular method selected to solve the problem. The solution demonstrates consistency with the system specifications.

Ability to Communicate Effectively - The MQP report describes the project clearly and completely. The report is constructed in such a manner that a person who was not associated with the MQP can understand the problem, the rationale behind the solution, and the final results.

Sensitivity to Global/Societal Context - The MQP report describes not only the technical aspects of the MQP, but also places the MQP into its appropriate context. For example, the report on a new robot arm controller design should place the new design in context with previous approaches by making comparisons on a basis of factors such as cost, utility, speed, and so on.

Need for Life-time Learning - The report illustrates that the student is aware that some of the limitations or failures of the MQP are a consequence of the current state of technology, or of the student's lack of understanding or experience. In either case, it is acknowledged that part of an engineer's job is to continually update and expand their knowledge and experience.

Sensitivity to Contemporary Issues - The report acknowledges that contemporary technical and non-technical issues may influence engineering design and shows how such issues were taken into account by the design. For example, an MQP involving automation might mention the associated need for retraining workers.

Use of Modern Engineering Tools and Techniques - The MQP was done using tools and techniques reflective of the current state-of-theart. Where appropriate computer simulations are performed to support analysis, the report is word processed, figures and schematics are drawn using CAD tools, and so on.

Multidisciplinary Robotics Knowledge - The MQP demonstrates multidisciplinary robotics knowledge from CS/ECE/ME core curricula.

\section{MOP Shows Acceptable Evidence Of}

The following paragraphs are intended as a guide to aid in consistently interpreting the "MQP Shows Acceptable Evidence Of" portion of the Project Outcomes and Assessment form.

Economic Considerations - The MQP report illustrates an awareness of economic concerns. Economic awareness is demonstrated by presenting data such as estimates of material cost, estimates of labor costs, optimizing cost versus performance, or computing life cycle cost. Safety Considerations - The report discusses any safety issues that arise relative to the use of the designed device. Proper use of the actual prototype for measurements or demonstrations without causing bodily injury to its operators is discussed. If the device is mass produced any issues that affect the welfare of technicians or end-users are presented. Proper handling of any materials or chemical processes that may have adverse effects on the environment are documented. The need for UL, FCC, or other approvals on the final hardware are discussed. Reliability Considerations - It is acknowledged in the report that a device must not only work, but it must work with a consistency that is reflective of the community expectations for the device. This goes hand in hand with testing (quality assurance, quality control) and analysis (reliability, availability, component tolerance). If the device is targeted at mass production, a set of tests to help eliminate units defective or unreliable units is presented. Mechanisms that could cause irreversible damage to the device are described.

Aesthetic Aspects - The report describes how aesthetic aspects such as power dissipation, weight, volume, form factor, and user interface are taken into consideration as a part of the design process.

Analysis - The report supports design decisions with an appropriate combination of mathematical analysis and simulation.

Synthesis - The report shows specifically how the design was created. This normally involves decomposing a high-level system specification into progressively lower level design specifications until a component level is reached.

Integration of Previous Course Work -

The MQP demonstrates that the student is able to integrate concepts from earlier courses into the solution of an engineering problem. Experimental Work - Analytical results, computer simulations, and compliance with specifications are verified by experimental measurements or certain aspects of the MQP's phenomenology are determined or verified through the use of well-formulated experiments. 
Appendix 2: MQP Content Analysis

Most frequently utilized terms in RBE MQP reports.

\begin{tabular}{lc}
\hline Term & No of repetitions \\
\hline robot & 889 \\
\hline control & 767 \\
\hline motor & 419 \\
\hline force/torque & 293 \\
\hline power & 273 \\
\hline sensor & 240 \\
\hline speed/velocity & 230 \\
\hline signal & 191 \\
\hline algorithm & 180 \\
\hline wheel & 152 \\
\hline software & 150 \\
\hline gear & 147 \\
current & 136 \\
\hline code & 132 \\
\hline program & 112 \\
\hline mechanical & 111 \\
\hline vision & 102 \\
\hline feedback & 86 \\
\hline voltage & 84 \\
\hline electric & 83 \\
\hline battery & 81 \\
\hline navigation & 76 \\
\hline pneumatics & 64 \\
\hline model & 64 \\
\hline encoder & 58 \\
\hline potentiometer & 56 \\
kinematic & 53 \\
\hline machine & 53 \\
\hline hydraulics & 48 \\
\hline pwm & 47 \\
\hline servo & \\
\hline electronic & 45 \\
\hline
\end{tabular}

$$
\begin{aligned}
& \mathbb{D} \\
& \mathbb{0} \\
& \mathbb{D} \\
& N \\
& \mathbb{N} \\
& \stackrel{N}{G} \\
& \vec{D}
\end{aligned}
$$

